\title{
Information needs and information seeking behaviour of small-scale farmers in Tanzania
}

\section{Edda Tandi Lwoga, Patrick Ngulube and Christine Stilwell}

Edda Tandi Lwoga

Information Studies

University of KwaZulu-Natal, Pietermaritzburg/

Sokoine National Agricultural Library,

Sokoine University of Agriculture, Tanzania

tlwoga@suanet.ac.tz

Patrick Ngulube

Department of Information Science

University of South Africa

ngulup@unisa.ac.za

Christine Stilwell

Information Studies

University of KwaZulu-Natal, Pietermaritzburg

Stilwell@ukzn.ac.za

\section{Abstract}

This article provides a review of the information needs and information seeking patterns of the rural farmers in selected districts of Tanzania. Focus group data was triangulated with interview data in order to validate, confirm and corroborate quantitative results with qualitative findings. The findings revealed that the information needs and information seeking patterns of farmers were location and gender specific to a certain extent. Farmers relied on interpersonal and face to face communication more than explicit sources of information. Constraints on information access included internal (personal) and external barriers (unavailability of the extension officers, distant locations for consultations with public extension officers, poor responses to information requests from the government and village leaders, lack of awareness of the available information sources, inability of some experts to solve problems, and 
poor knowledge sharing culture). It is thus important for the government to improve access to extension services, and equip them with necessary skills and adequate information resources. Further, the public and extension services, researchers, educators, information services and other agricultural actors should conduct regular studies on information needs, map communities' knowledge and information sources, create awareness of information sources, and knowledge culture, and use multiple sources of information (such as print and ICTs) to deliver relevant information in the communities in order to meet the disparate farmers' needs.

\section{Background and context}

Knowledge about the information needs and information seeking behaviour of small-scale farmers is crucial to effectively satisfy their felt information needs and develop demand-led extension and advisory services (Garforth 2001). With relevant agricultural knowledge and information, farmers could improve their work in order to sustain agriculture and also benefit economically (LesaoanaTshabalala 2003). The agricultural sector is an important instrument for development and a source of livelihood in Africa. In Tanzania, this sector is the backbone of the economy, and accounts for more than $25.7 \%$ of gross domestic product (GDP), provides $30.9 \%$ of exports, and employs $70 \%$ of the work force (URT 2009). Hence, effective access to relevant information is essential for improving agricultural productivity and bringing about social and economic change in African countries including Tanzania. Studies have revealed that there is a positive relationship between an increased flow of knowledge and information (from sources such as information centres) and agricultural development in Tanzania (Mchombu 2001;2003).

Despite its potential for agricultural development, most African countries have not devoted their efforts to disseminating knowledge and information, especially in rural areas, where 70 to $80 \%$ of the African population lives (Adomi, Ogbomo and Inoni 2003). Only a small amount of information on various innovations is known to the majority of small-scale farmers (Ochieng 2004), despite the large body of information and knowledge that exists in research institutions, universities, public offices and libraries. Weak linkages between research, extension, not for profit organizations, libraries and farmers have contributed to this situation and thus new knowledge and technologies have neither reached nor been adopted by their intended beneficiaries to improve their farming activities in developing countries including Tanzania (MAFS 2001; Tire 2006). A study by the International Institute for 
Communications and Development (IICD) in 2003 of global and national agricultural information systems revealed a disjuncture between the information needs of farmers and the information provided by the research and education sector, which was insufficiently localized and overly scientific in its presentation (Besemer, Addison and Ferguson 2003). The provision of more meaningful options that meet farmers' needs rather than prescriptions can enhance the adoption of agricultural knowledge and information for improved farming activities in the developing countries. Therefore, this study mainly sought to establish the information needs and information seeking behaviour of the small-scale farmers for improved access to relevant information in the rural areas and sustainable agricultural activities in developing countries, with a particular focus on small-scale farmers in Tanzania. It is with this background that the following research objectives were posed:

- To determine farmers' information and knowledge needs;

- To assess the information seeking patterns of the small-scale farmers; and

- To identify constraints that limited farmers from seeking information and knowledge in the local communities.

A brief background on information needs, information seeking of farmers and their application in the context of developing countries is also presented.

\section{Information needs and information seeking behaviour}

An information need is described as a recognition that personal knowledge is inadequate to satisfy a goal that needs to be achieved (Case 2002: 5). Information needs can be recognised by the information seeker or by the information expert on behalf of the information seeker. However, the information seeker and an expert may need to work together towards “disentangling” and establishing the actual information needs (Kaniki 2001). As part of the search for the satisfaction of these needs, an individual may engage in information seeking behaviour (Wilson 1981). Information seeking behaviour (ISB) is purposive in nature and is an outcome of a need to satisfy some objectives. In the course of seeking, the individual may interact with people, face to face or electronically (Wilson 2000). Thus, the individual recognises an inadequacy in his/her knowledge that needs to be resolved in order to deal with a problem, which then results in information seeking behaviour. 


\section{Information seeking behaviour in rural communities}

Regular studies are important for updating farmers' information needs in order to accommodate changes in the farmers' environment (Kalusopa 2005). Longitudinal studies are necessary because the level of need for similar information may differ over time and between persons or groups of persons depending on a variety of factors, such as the demographics of education, age, social and economic backgrounds, or by those factors that are resource based, namely, availability of information, awareness of availability, acquaintance with, and ease of use of information resources (Kaniki 2001). Various studies have also confirmed that the information needs of small-scale farmers are personal and location specific, such as in Lesotho (Lesaoana-Tshabalala 2003), rural India (Meitei and Devi 2009) and Tanzania (Matovelo, Msuya and de Smet 2006). By assessing those needs, the service providers are able to understand and design more effective information systems (Wilson 1981), and farmers are able to access relevant information and knowledge which would solve their problems and improve their farming activities.

Research on the knowledge and information sources used by most information seekers, especially in the rural areas of developing countries, has shown that local people mainly seek to obtain knowledge and information from informal rather than formal sources. In Ghana, Chisenga, Entsua and Sam (2007) found that poultry farmers mainly sought their knowledge and information from farmer associations, followed by fellow farmers, radio and television. In Zambia apart from obtaining information from non-governmental organisations (NGOs), most farmers relied on personal experience, and informal networks (family, friends, and colleagues) to meet their information needs (Kalusopa 2005). Conversations with friends, relatives, and neighbours were found to be major sources of knowledge and information in similar information behaviour studies in Zambia (Kaniki 1994), with rural dwellers in India (Chakrabarti 2001) and Tanzania (Chilimo 2009), and with fishermen in Uganda (IkojaOdongo and Ocholla 2003) and Nigeria (Njoku 2004). Mass media such as radio, television and newspapers were a major source of knowledge and information for the majority of rural poor in Manipur (Meitei and Devi 2009) and Nigeria (Momodu 2002). Generally, these studies indicate that farmers rely on the informal networks and, to a lesser extent, the mass media to meet their information needs. In an analysis of twelve articles on information behaviour of urban and rural dwellers in developing countries, Dutta (2009) also concluded that people mainly rely upon informal social networks to meet their information needs. 
Certain factors may interfere positively or negatively in the process of information seeking, and thus create barriers to obtaining useful information. Various scholars have illustrated these issues. Wilson (1996) described these factors as personal, emotional, educational, demographic, social/interpersonal, environmental, economic, and source characteristics. Other barriers may include high cost, illiteracy, and lack of information and communication technology (ICT) infrastructure (Aina 2004), which may fall within Wilson's (1996) category of "intervening variables." Other barriers include culture, social, psychological and behavioural characteristics (Hepworth 2007). Many empirical findings have revealed these barriers in developing countries. For instance, internal (personal) and external or environmental factors were perceived as major barriers that hindered information seeking by informal entrepreneurs (Ikoja-Odongo and Mostert 2006) and fishermen in Uganda (Ikoja-Odongo and Ocholla 2003). Dutta (2009) also revealed that illiteracy, extension workers with insufficient knowledge, and the digital divide were the major obstacles for meeting information needs of rural dwellers in eight developing countries. Overall, the main focus should be on the identification of local community needs, and information seeking behaviour in order to provide relevant information and knowledge services. It is thus important to conduct a study on information needs, and information seeking behaviour of the rural farmers for improved agricultural information and knowledge provision strategies in the rural areas.

\section{Methodology}

This study used qualitative and quantitative approaches. The former was the dominant approach because of its usefulness in studying human action in a natural setting and in attempting to make sense of, or interpret, phenomena in terms of the meanings people bring to them (Denzin and Lincoln 2005: 3). The quantitative approach allows patterns of information seeking and use to be rigorously described. Purposive sampling was used to select research sites and study participants because it is confined to specific types of people who can provide the desired information, either because they are the people who have it, or they conform to some criteria set by the researcher (Sekaran 2003: 277). Six districts from six zones out of seven research zones were selected for the study due to their high agricultural production and presence of ICTs such as telecentres, community radio, and cellular telephone networks. Two villages were purposively selected from each of the six districts due to their high agricultural production. These districts and villages included the following: Mpwapwa district (Vinghawe and Mazae villages), Karagwe district (Katwe 
and Iteera villages), Moshi Rural district (Lyasongoro and Mshiri villages), Kilosa district (Kasiki and Twatwatwa villages), Songea Rural district (Matetereka and Lilondo villages), and Kasulu district (Nyansha and Kidyama villages). The qualitative data were collected through semi-structured interviews and focus groups, while quantitative data were gathered using closed questions posed to respondents during the same interviews. A total of twelve focus group sessions were held in the surveyed villages, where one focus group session was held per village. One hundred and twenty eight respondents were purposively selected to participate in the focus groups' discussions, where the study participants ranged between six and twelve respondents per session. Further, 181 small scale farmers were purposively selected to participate in the semistructured interviews, where the number of respondents ranged between 27 and 37 per region. The identification of the study participants was based upon discussions with community leaders and local extension officers in each stratum in order to cover a broad spectrum of farming systems, ethnic-religious groups, gender and age groups. These characteristics were used because variations in knowledge can be observed according to diversity in agro-ecology, ethnicity, population density and infrastructure (Röling 1989). Interviews and focus group sessions were terminated when it was judged that the point of redundancy had been reached and no new information was forthcoming, thus determining the final sample size (Patton 2002: 246). Qualitative analysis involved the process of categorisation of themes contained in data, followed by linking of themes and ideas and exploring new ideas (Pickard 2007: 280). SPSS was used to analyse the quantitative data that emanated from the set of closed-ended questions in the semi-structured interviews. Frequencies, percentages and forms of graphic presentation were used to represent the quantitative data from semi-structured interviews.

\section{Results and discussion}

This section presents the study findings according to the following themes: information needs, information seeking patterns, and the constraints on information seeking. The profile of the respondents is also presented.

\section{Profile of respondents}

A total of 181 smallholder farmers (112 men and 69 women) participated in the semi-structured interviews. The gendered nature of the social, cultural, economic and policy systems may have limited women farmers from participating in the study. The mean age of the respondents was 48 , with the 
majority of respondents $(74.6 \%$; 135) between the ages of 29 and 68 years. The average farm size was 4.9 acres, where the majority of the crop farmers (61.9\%; 104) had farms smaller than 4.9 acres in extent. The majority of the respondents (84\%; 152) had some level of formal schooling and 91.2\% (163) could read and understand simple instructions. Among those with formal schooling, male respondents dominated the higher education category.

A total of 128 smallholder farmers participated in the focus group discussions, of which slightly more than half (50.8\%; 65) were male, and about $49.2 \%$ (63) were female. The mean age of the respondents was 45 , with the majority of respondents $(78.1 \% ; 100)$ between the ages of 29 and 68 years. One hundred and fourteen (89.1\%) respondents had some level of formal schooling and about $90.7 \%$ (116) could read and understand simple instructions. Among those (89.1\%; 114) with formal schooling, male respondents dominated the higher education category compared to women. Male respondents accounted for $41.4 \%$ (48) of those with primary school education, 8.6\% (10) with secondary education, $1.7 \%$ (2) with post-secondary education, and $0.9 \%$ (1) with some form of adult education.

\section{Farmers' information needs}

From semi-structured interviews, the study found that while knowledge is needed for all farming activities, the following categories were the main knowledge gaps for the small scale farmers (Table 1): control of plant diseases and pests (66.3\%; 120), marketing (59.1\%; 170), credit and loan facilities (58.6\%; 106), and control of animal diseases (54.7\%; 99). Irrigation practices $(29.3 \%$; 53) had low rates of response. In this study, the respondents could indicate more than one need, hence percentages do not total 100 . The study findings indicated that other knowledge gaps were the lack of early warning systems and environmental conservation. It is obvious that farmers were concerned with subjects that directly affected their farming activities. However, knowledge needs varied across the surveyed districts, as shown in Table 1, most likely because of differences in agricultural activities, agro-ecological conditions, the state of development per village, as well as the availability of active knowledge intermediaries, such as extension officers and NGOs, in the district. The study findings showed that control of plant diseases and pests was a major knowledge need for farmers in Kasulu (13.3\%; 24), Karagwe (13.3\%; 24), and Moshi Rural (12.2\%; 22). Agricultural marketing was the main knowledge need for farmers in Kilosa (17.7\%; 32), and Karagwe (14.9\%; 27). Knowledge on credit facilities and control of animal diseases was a great 
concern for farmers in Kilosa (18.8\%; 34). Soil classification (9.9\%; 18) was a main knowledge need for Songea Rural's farmers. These findings were similar to those of other studies on agricultural information needs in Eritrea (Garforth 2001), Kenya and South Africa (Kwake and Ocholla 2007), Lesotho (LesaoanaTshabalala 2003), India (Meitei and Devi 2009), and Tanzania (Matovelo, Msuya and de Smet 2006).

Table 1: Information and knowledge needs of small-scale farmers in six districts of Tanzania $(n=181)$

\begin{tabular}{|c|c|c|c|c|c|c|c|c|c|c|c|c|c|c|}
\hline \multirow{3}{*}{$\begin{array}{l}\text { Information } \\
\text { and } \\
\text { knowledge } \\
\text { needs }\end{array}$} & \multicolumn{14}{|c|}{ District } \\
\hline & \multicolumn{2}{|c|}{ Mpwapwa } & \multicolumn{2}{|c|}{ Karagwe } & \multicolumn{2}{|c|}{ Kasulu } & \multicolumn{2}{|c|}{$\begin{array}{l}\text { Moshi } \\
\text { Rural }\end{array}$} & \multicolumn{2}{|c|}{ Kilosa } & \multicolumn{2}{|c|}{$\begin{array}{l}\text { Songea } \\
\text { Rural }\end{array}$} & \multicolumn{2}{|c|}{ Total } \\
\hline & No & $\%$ & No & $\%$ & No & $\%$ & No & $\%$ & No & $\%$ & No & $\%$ & No & $\%$ \\
\hline $\begin{array}{l}\text { Soil } \\
\text { classification }\end{array}$ & 8 & 4.4 & 6 & 3.3 & 9 & 5 & 11 & 6.1 & 20 & 11 & 18 & 9.9 & 72 & 39.8 \\
\hline $\begin{array}{l}\text { Crop } \\
\text { varieties }\end{array}$ & 11 & 6.1 & 11 & 6.1 & 18 & 9.9 & 17 & 9.4 & 22 & 12.2 & 8 & 4.4 & 87 & 48.1 \\
\hline $\begin{array}{l}\text { Crop } \\
\text { husbandry }\end{array}$ & 6 & 3.3 & 8 & 4.4 & 8 & 4.4 & 13 & 7.2 & 20 & 11 & 3 & 1.7 & 58 & 32 \\
\hline Irrigation & 4 & 2.2 & 3 & 1.7 & 13 & 7.2 & 12 & 6.6 & 19 & 10.5 & 2 & 1.1 & 53 & 29.3 \\
\hline $\begin{array}{l}\text { Agricultural } \\
\text { tools }\end{array}$ & 16 & 8.8 & 22 & 12.2 & 14 & 7.7 & 11 & 6.1 & 21 & 11.6 & 5 & 2.8 & 89 & 49.2 \\
\hline $\begin{array}{l}\text { Animal } \\
\text { feeding }\end{array}$ & 2 & 1.1 & 8 & 4.4 & 8 & 4.4 & 19 & 10.5 & 31 & 17.1 & 2 & 1.1 & 70 & 38.7 \\
\hline $\begin{array}{l}\text { Animal } \\
\text { breeding }\end{array}$ & 4 & 2.2 & 3 & 1.7 & 8 & 4.4 & 13 & 7.2 & 31 & 17.1 & 2 & 1.1 & 61 & 33.7 \\
\hline $\begin{array}{l}\text { Credit } \\
\text { facilities }\end{array}$ & 10 & 5.5 & 17 & 9.4 & 16 & 8.8 & 15 & 8.3 & 34 & 18.8 & 14 & 7.7 & 106 & 58.6 \\
\hline $\begin{array}{l}\text { Land } \\
\text { preparation }\end{array}$ & 6 & 3.3 & 3 & 1.7 & 11 & 6.1 & 13 & 7.2 & 20 & 11 & 1 & 0.6 & 54 & 29.8 \\
\hline $\begin{array}{l}\text { Soil } \\
\text { fertilization }\end{array}$ & 7 & 3.9 & 14 & 7.7 & 20 & 11 & 12 & 6.6 & 21 & 11.6 & 13 & 7.2 & 87 & 48.1 \\
\hline $\begin{array}{l}\text { Value } \\
\text { added }^{1}\end{array}$ & 10 & 5.5 & 4 & 2.2 & 10 & 5.5 & 12 & 6.6 & 22 & 12.2 & 7 & 3.9 & 65 & 35.9 \\
\hline Marketing & 7 & 3.9 & 27 & 14.9 & 11 & 6.1 & 15 & 8.3 & 32 & 17.7 & 15 & 8.3 & 107 & 59.1 \\
\hline $\begin{array}{l}\text { Animal } \\
\text { housing }\end{array}$ & 2 & 1.1 & 5 & 2.8 & 8 & 4.4 & 13 & 7.2 & 27 & 14.9 & 2 & 1.1 & 57 & 31.5 \\
\hline $\begin{array}{l}\text { Animal } \\
\text { diseases }\end{array}$ & 11 & 6.1 & 16 & 8.8 & 19 & 10.5 & 16 & 8.8 & 34 & 18.8 & 3 & 1.7 & 99 & 54.7 \\
\hline $\begin{array}{l}\text { Plant } \\
\text { diseases and } \\
\text { pests }\end{array}$ & 21 & 11.6 & 24 & 13.3 & 24 & 13.3 & 22 & 12.2 & 17 & 9.4 & 12 & 6.6 & 120 & 66.3 \\
\hline
\end{tabular}

(Multiple responses were allowed) 
It was evident from the focus group discussions that information on agricultural markets was the main information need in the communities as indicated by eight focus groups in five districts, followed by information on value added techniques, and credit as indicated by seven focus groups in five districts. Information on the control of animal diseases, animal breeds and crop varieties, and control of plant diseases and pests were also important information needs in the local communities. Other information needs as indicated in the focus group discussions included the following: agricultural tools; soil classification and fertility; irrigation practices, land rights and leases; crop husbandry practices, animal husbandry practices; environmental conservation; formation of farmer groups; and early warning systems. Although data collected through interviews showed that plant diseases, agricultural markets, credit and loan facilities, and control of animal diseases were the major concern for farmers in the surveyed communities, the focus groups indicated that information on agricultural markets, value added techniques, and credit were the main information needs in the communities. Despite the discrepancies, broad categories can be drawn that the following were the major knowledge gaps in the communities: plant and animal diseases, agricultural markets, value added techniques, and credit.

Further analysis showed that there were slight variations in the information and knowledge needs according to gender as depicted in Figure 1. Females mainly needed knowledge on value added techniques (42\%; 29), crop planting (36.2\%; $25)$, and irrigation (33.3\%; 23), while males needed knowledge on agricultural marketing (62.5\%; 70), and soil fertility (50.9\%; 57). These findings corroborate the results of studies carried out in other African countries which reported that there was a gender split in the information needs in Eritrea (Garforth 2001) and Nigeria (Adomi, Ogbomo and Inoni 2003). It could thus be important for rural information initiatives to focus on the different information needs of males and females in each district. 


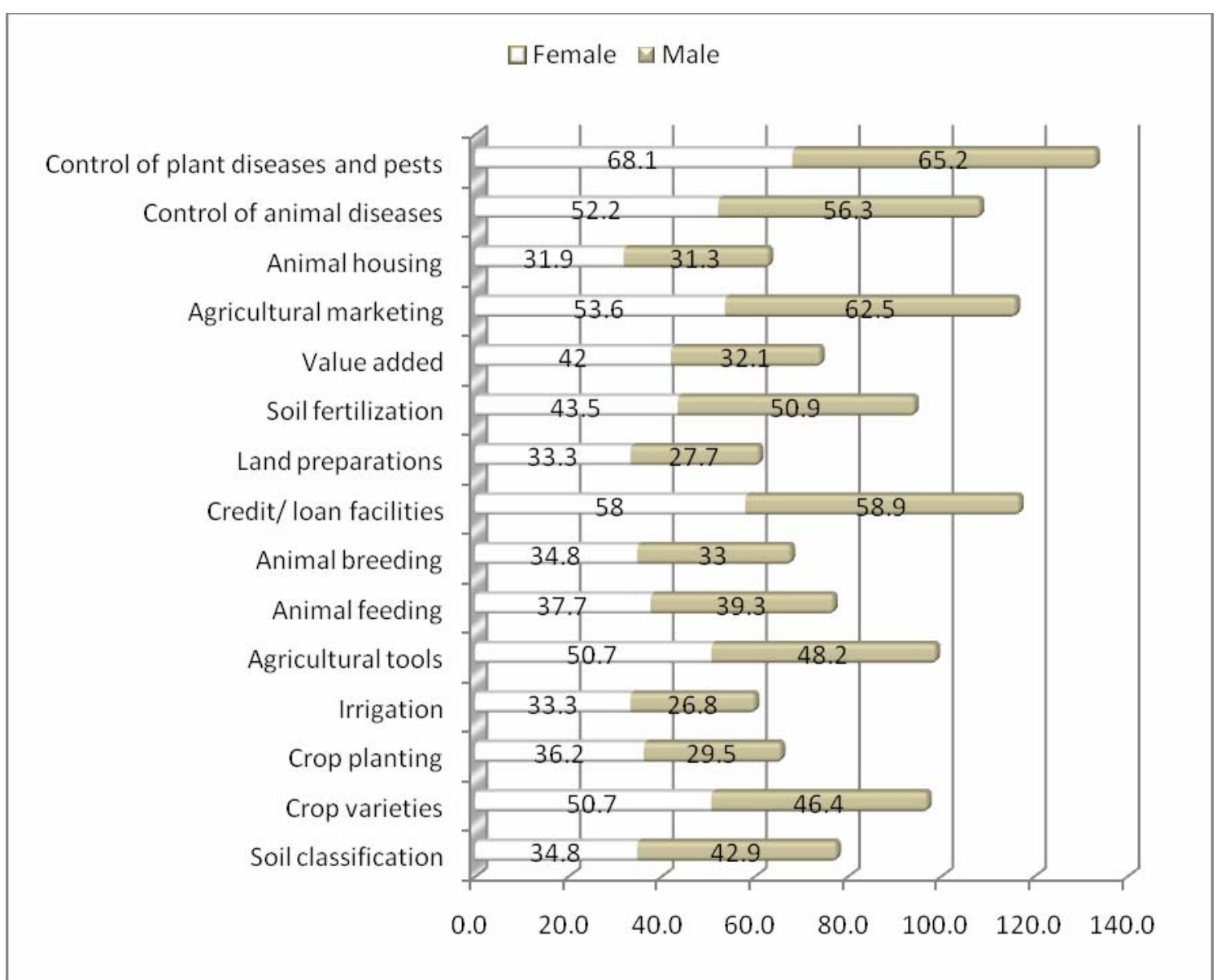

Figure 1: Farmers’ information needs by gender $(n=181)$

\section{Information seeking patterns}

Just more than half of the respondents in the interviews (51.4\%; 93) had tried to look for ways to solve their information-related problems, while $48.6 \%$ (88) had not. Although the study findings indicated that slightly more than half of the respondents had tried to look for ways to solve their knowledge problems, a study by Chilimo (2008) reported a higher percentage, 93\% (of 114 respondents) of rural people who had attempted to find information to fulfil their needs in the rural areas of Tanzania. In the present study, of the respondents who had tried to find ways to solve their information-related problems (51.4\%; 93), more than half (57\%; 53) had managed to solve part of their problem. Although more than half of the respondents in this study had managed to solve part of their knowledge problems, a study by Ikoja-Odongo (2001) indicated a higher percentage of the informal entrepreneurs (87.5\%) in Uganda who were able to find the information they wanted. The findings of the present study and previous studies show that farmers had various means of identifying and locating knowledge to fulfil their knowledge needs. These 
findings also mean that there is a need to create a culture that would encourage farmers to seek knowledge in order to fulfil their needs and improve their farming activities.

It was evident from the findings of the present study that farmers largely sought information from friends/neighbours (43\%; 40), extension officers (35.5\%; 33), agricultural input suppliers, $(17.2 \% ; 16)$ and family/parents $(17.2 \% ; 16)$. Other knowledge sources included farmer groups $(11.8 \%$; 11$)$, personal experience (10.8\%; 10$)$, village leaders (7.5\%; 7), NGOs (4.3\%; 4), district officials (4.3\%; 4 ), radio (4.3\%; 4 ), village meetings ( $3.2 \%$; 3 ), middlemen (3.2\%; 3 ), and farmer cooperatives (2.2\%; 2). Farmers made little use of other knowledgeable farmers, printed materials (that is, books, newsletters, leaflets, posters), and television, with a score of $(1.1 \%$; 1$)$ each. There were low responses to a question that analysed farmer's information seeking patterns because the question was open-ended. Overall, the study findings were similar to other studies of rural farmers in Zambia (Kalusopa 2005), rural women in Botswana (Mooko 2005), and Nigerian fishermen (Njoku 2004), which showed that friends, relatives and neighbours were the major sources of information in rural areas. The findings also suggested that farmers mainly depended on informal networks of friends/neighbours, parents and formal contacts with input suppliers and extension officers rather than on explicit sources of knowledge in the surveyed communities.

Data obtained from the focus groups confirmed that most respondents from nine focus group discussions in all districts had tried to look for ways to solve their farming problems. For their information and knowledge needs, farmers mainly consulted the extension officers and village leaders. Public extension officers were largely consulted by farmers in Moshi Rural (Mshiri Village), Karagwe (Iteera Village), and Kasulu (Nyansha Village). Village leaders were important in Karagwe (Iteera Village), and Mpwapwa (Mazae and Vinghawe Villages). For instance, farmers in Karagwe (Iteera Village) indicated that, "we have a procedure of informing the extension officer or village leaders in case of a problem such as plant disease outbreaks, for example banana panama.” Farmers in Mpwapwa (Mazae Village) also reported that, "we follow a normal channel where we discuss our problems at the village meetings, and then we forward them to the ward, division and district meetings. However, the district authority has been too slow to respond to our needs.” The study findings from focus group discussions further showed that neighbours, district authorities, and agricultural input suppliers were also important sources of knowledge and information which farmers consulted, followed by libraries and agricultural researchers. Neighbours were mainly identified in Kigoma (Nyansha Village), 
and Dodoma (Mazae Village), as important sources of knowledge in case of problems. For instance, farmers in Kigoma (Nyansha village) said that, "we go to our neighbours to seek for advice whenever they have a problem. We observe what our neighbours are doing and copy from them.” District authorities were also consulted by farmers in Morogoro (Kasiki Village), and Dodoma (Mazae Village). Agricultural shops were important sources of information in Kagera (Katwe Village) and Morogoro (Twatwatwa Village), while libraries were consulted by farmers in Morogoro (Kasiki Village) and researchers were significant in Ruvuma (Materereka Village).

Although the interview findings showed that farmers largely sought information from friends/neighbours and extension officers, data obtained from focus group discussions indicated that farmers mainly consulted the extension officers and village leaders to fulfil their information needs, followed by neighbours and district authorities. Despite the discrepancies between the study findings from interviews and focus groups, major patterns can be identified, showing that farmers largely sought information from friends/neighbours, and extension officers in the local communities. Village leaders, district authorities, agricultural input suppliers, and family/parents were also important sources of information consulted by farmers.

\section{Constraints on information seeking}

Data from the semi-structured interviews indicated that the unavailability of extension officers was the major problem that hindered farmers from obtaining information, followed by a lack of awareness of information sources and distant locations for consultations with public extension officers. These problems, arranged in descending order of importance, are explained in detail below.

\section{Unavailability of public extension officers}

Most of the surveyed communities either lacked extension officers or they had only a few extension officers to assist them when they had problems. In Kilosa (Kasiki Village), for example one respondent reported that "there is no need to seek information or consult veterinary officer to control animal diseases because they are few." Farmers in Karagwe (Iteera and Katwe villages), and Kasulu (Nyansha and Kidyama villages) did not have extension officers, and they lacked funds to travel to the district headquarters for consultations with the extension officers in case of problems. Further, most extension officers were 
ignorant about indigenous farming techniques, and thus farmers were reluctant to seek information from them.

\section{Lack of awareness of information sources}

Farmers were not aware of their right to consult formal sources of knowledge, such as extension officers or district officers through their village leaders, once they had a problem. Thus, most of them depended on the informal sources of knowledge such as family, neighbours and friends, who at times were not sufficiently knowledgeable or reliable to solve their problems. For instance, in Kilosa (Kasiki Village), one respondent indicated that, "I am scared to apply for a loan because I'm illiterate, old and there are difficult conditions to access credits." Another respondent in Kasulu (Nyansha) reported that, "lack of understanding on where else to get information apart from my family and neighbours has hindered me to solve some of the problems I encounter in my farming activities.”

\section{Location}

Concerns were raised about the long distance that farmers had to travel to consult the extension officers at the district headquarters or in other villages, or to negotiate prices with middlemen. For instance, farmers in Kasulu and Karagwe were located very far from district headquarters and they lacked village extension officers. The Songea Rural's farmers were also located very far from the district market, and thus it was difficult for them to access reliable market information. For instance, one farmer in Songea Rural reported that, "the market is too far to get reliable information on markets. Thus, I only consult my neighbours and friends who do not have accurate information.”

\section{Socio-economic and social factors}

Socio-economic status and age limited some farmers to seek knowledge from their fellow farmers, farmer groups, village authorities and extension officers. For instance, farmers especially in Songea Rural, Moshi Rural, Kilosa, and Kasulu reported that they were too old to seek information and knowledge from the various sources that existed within and outside their villages. For instance, one farmer in Kilosa (Kasiki Village) indicated that, "I am not able to join any farmer groups because I'm too old. Thus, I rely on my neighbours and family for advice when I have a problem.” Another farmer in Kasulu (Kidyama village) said that, "I am too old to attend village meetings about agriculture. 
Therefore, I rely on my neighbours and family for advice when I have a problem.”

\section{Resistance to change}

Some farmers were resistant to change and, due to ignorance and lack of encouragement from their leaders, did not seek and adopt new information and knowledge. In Kilosa (Twatwatwa Village) for example, some respondents indicated that they were not willing to learn from other farmers because they preferred to draw on their own personal experience. Other farmers in Kasulu (Kidyama Village) indicated that they were not encouraged or motivated by their village leaders to consult their fellow farmers in case of farming problems.

\section{Inability of some experts to solve problems}

Some farmers in Moshi Rural and Kilosa were discouraged from seeking information and knowledge from within and outside their villages because some of that knowledge was not effective in solving their problems. Typical responses included:

“....I contacted the extension officer and she told me to uproot the banana plant and leave the banana pit open in order to treat kisoli (banana weevil) disease. However, I have not been successful to control the disease."

“......I consulted the agricultural input supplier and I was told to use vaccines for Newcastle poultry disease. However, I have not been successful to control the disease.”

\section{Selfishness}

Some farmers were selfish about sharing their knowledge, which limited other farmers in seeking knowledge and information. For instance, one farmer in Kilosa (Kasiki Village) reported that there was little cooperation from neighbours when one wants advice on agricultural activities. Some farmers in Kilimanjaro (Lyasongoro Village) indicated that others would benefit if they shared their knowledge.

\section{Nature of small-scale farming}

Most farmers felt that there was no need to seek information and knowledge to solve their farming problems because they farmed on a small scale. 


\section{Needing a record for future reference}

One respondent in Kilosa (Kasiki Village) indicated that,

it is difficult to access knowledge through radio because one has to memorize what is aired from the radio programmes. Instead, I would prefer knowledge to be delivered through printed format such as newspapers for future reference.

Some data collected through focus groups confirmed findings obtained from the interviews. The focus groups confirmed that the unavailability of extension officers was a major problem which limited farmers from seeking information as identified in all focus group discussions. Other factors that inhibited farmers from seeking information in their communities included the following: poor response from government authorities in terms of requests for information was an important problem in Kilosa (Kasiki Village), Mpwapwa (Mazae and Vinghawe Villages) and Songea Rural (Matetereka Village); lack of awareness on the available sources of knowledge and information and their right to seek knowledge and information was a significant problem which limited farmers from seeking information in Kasulu (Kidyama Village), Kilosa (Kasiki Village) and Songea Rural (Lilondo Village); and poor knowledge sharing culture was a key problem which inhibited farmers from seeking information in Kilosa (Twatwatwa Village) and Songea Rural (Lilondo Village). Other factors were high charges for library services, selfishness, socio-economic factors, high costs and unavailability of inputs and tools, illiteracy, and lack of funds to purchase printed materials or to travel to other villages or district headquarters for consultations with extension officers.

On the whole, data from interviews and focus groups showed that major factors that inhibited respondents from seeking information and knowledge were related to the unavailability of extension officers, lack of awareness of information sources, distant locations for consultations with public extension officers, poor response to information requests from the government and village leaders, lack of awareness on the available sources of knowledge and information and their right to seek knowledge and information, poor knowledge sharing culture, and personal barriers (that is, age, gender, resistance to change, and selfishness). These barriers correspond with Ikoja-Odongo and Mostert's (2006) categories of internal (personal) and external or environmental factors (such as, illiteracy, culture, poor information services, costly information materials, poverty, and the multiplicity of local languages) which inhibited Ugandan informal entrepreneurs from seeking information. In Tanzania, 
Chilimo (2009) reported that local communities did not tackle their problems because of ignorance, low social status, and the unavailability of the extension officers. Similarly, illiteracy and language barriers limited rural dwellers from seeking information in Nigeria (Momodu 2002). Similar findings were reported in the information seeking studies of Nigerian fishermen (Njoku 2004), and South African urban dwellers (Zaverdinos-Kockott 2004). These findings indicate that farmers did not have a culture of sharing and learning from others due to many factors including personal, social and resource based factors, and thus they tended to ignore new information.

\section{Conclusions and recommendations}

The study findings showed that there was a large knowledge gap in the sampled districts due to external barriers (that is, unavailability of the extension officers, distant location for consultations with public extension officers, poor response to information requests from the government and village leaders, lack of awareness on the available information sources, inability of some experts to solve problems, and poor knowledge sharing culture), and personal barriers (that is, age, gender, resistance to change, memory lapses and selfishness).

While, it is important to nurture a culture of learning and sharing in the local communities, it is also important to map information sources for easy identification of knowledge bearers. The government should also address finance and resource-based problems (such as adequate numbers of extension officers, information materials, and literacy levels, agricultural inputs, and improvements in telecommunications and road infrastructures) for effective extension and research services. Further, the findings showed that the information needs were location and gender specific to a certain extent which indicates that individuals may have different levels of knowledge on farming systems, and various information needs which may dictate different patterns of seeking information to fulfil their needs. It is thus important for the information providers (such as, the government and private extension services, and other agricultural information actors) to have a good knowledge of these specific needs and specifically tailor their information products and services to meet these disparate needs, rather than employing a uniform information delivery/sharing strategy in the local communities.

The study findings from interviews and focus groups showed that farmers largely sought information from friends/neighbours and extension officers to fulfil their information and knowledge needs. Village leaders, district 
authorities, agricultural inputs suppliers, and family/parents were also important sources of information which farmers consulted. Farmers made little use of ICTs (that is radio and television), and printed materials. This study can also conclude that local communities are more likely to use face-to-face communication than explicit sources of information (such as, books, newsletters, leaflets) to fulfil their needs. Based on study findings, this study recommends the following:

- Government should improve access to public extension services, by increasing the number of extension officers, and providing adequate training programmes to update their skills in the farming activities. The government should also provide adequate resources to the extension officers such as information materials, and agricultural inputs in order to fulfil farmers' needs;

- The rural information services (that is, agricultural extension officers, researchers, educators, libraries, and other agricultural actors) need to conduct regular studies on information needs in order to fulfil the communities' needs and improve farming activities in the rural areas;

- Needs assessments should also be used to map communities' knowledge and information sources in order to enable local farmers to locate agricultural experts in their communities;

- Rural information services (that is, agricultural extension officers, researchers, educators, libraries, and other agricultural actors), government departments and village authorities should work together to create awareness of the available information sources, and promote a culture of learning and sharing to enable the communities to seek advice when they have a problem and share their knowledge. These leaders and information services should encourage active participation and involvement of farmers in various processes that deal with knowledge sharing and learning in the villages, such as farmer groups, knowledge sharing forums, community of practices, village meetings, and other related activities to enable farmers to share and learn from each other. The government should strengthen the social capital of the local leaders and their roles in knowledge and information sharing and learning activities should be properly defined; and

- Multiple sources of information and knowledge, including print and electronic information, should be made available to ensure farmers have access to relevant knowledge. Print formats (such as leaflets, newsletters, books) and ICTs such as internet, e-mails and cellular telephones can be used to share and distribute knowledge among farming communities to supplement what was gained verbally. 


\section{References}

Adomi, E. E., Ogbomo, M. O. and Inoni, O. E. 2003. Gender factor in crop farmers' access to agricultural information in rural areas of Delta State, Nigeria. Library review 52(8): 388-393.

Aina, L. O. 2004. Towards improving information access by semi and nonliterate groups in Africa: a need for empirical studies of their information seeking and retrieval patterns. In Bothma, T. and Kaniki, A. (eds). ProLISSA: proceedings of the third biennual DISSAnet Conference, Progress in Library and Information Science in Southern Africa, Pretoria, 28-29 October. Pretoria: Infuse. Pp. 11- 20.

Besemer, H., Addison, C. and Ferguson, J. 2003. Fertile ground: opportunities for greater coherence in agricultural information systems. DFID 19. Hague: IICD. Available at: http://www.ftpiicd.org/files/research/reports/report19.pdf. Accessed 20 March 2007.

Case, D. O. 2002. Looking for information: a survey of research on information seeking, needs and behaviour. Amsterdam: Academic Press.

Chakrabarti, B. 2001. Over the edge of information in the information age: information behaviour of the Totos: a small marginal tribal community in subHimalayan North Bengal, India. The international information and library review 33 (180): 167-180.

Chilimo, W. L. 2009. Information and communication technologies and sustainable livelihoods: a case of selected rural areas of Tanzania. PhD. University of KwaZulu-Natal, Pietermaritzburg, South Africa.

Chisenga, J., Entsua-Mensah, C. and Sam, J. 2007. Impact of globalization on the information needs of farmers in Ghana: a case study of small-scale poultry farmers. Paper read at the World Library and Information Congress: 73rd IFLA General Conference and Council Durban, South Africa, 19-23 August 2007. Available at: http://www.ifla.org/iv/ifla73/index.htm. Accessed 22 August 2009.

Denzin, N. K. and Lincoln, Y. S. 2005. Introduction: the discipline and practice of qualitative research. In Denzin, N. K. and Lincoln, Y. S. (eds). The sage handbook of qualitative research, 3rd ed. Thousands Oaks: Sage. Pp. 1-32. 
Dutta, R. 2009. Information needs and information seeking behaviour in developing countries: a review of the research. The international information and library review 41 (1): 44-51.

Garforth, C. 2001. Agricultural knowledge and information systems in Hagaz, Eritrea. Available at: http://www.fao.org/sd/2001/KN1001a_en.htm. Accessed 3 April 2007.

Hepworth, M. 2007. Knowledge of information behaviour and its relevance to the design of people-centred information products and services. Journal of documentation 63 (1): 35-56.

Ikoja-Odongo, R. 2001. A study of the information needs and uses of the informal sector in Uganda: preliminary findings. Library and information science research 11 (1). Available at:

http://libres.curtin.edu.au/libres11n1/ocholla.htm. Accessed 20 June 2009.

Ikoja-Odongo, R. and Ocholla, D. N. 2003. Information needs and information seeking behaviour of artisan fisher folk of Uganda. Library and information science research 25 (1): 89-105.

Ikoja-Odongo, R. and Mostert, B. J. 2006. Information seeking behaviour: a conceptual framework. South African journal of libraries and information science 72 (3): 145-158.

Kalusopa, T. 2005. The challenges of utilizing information communication technologies (ICTs) for the small-scale farmers in Zambia. Library hi tech 23 (3): 414-424.

Kaniki, A. M. 1994. Information seeking and information providers among Zambian farmers. Libri 41: 147-169.

Kaniki, A. M. 2001. Community profiling and needs assessment. In Stilwell, C., Leach, A. and Burton, S. (eds). Knowledge, information and development: an African perspective. Pietermaritzburg: University of KwaZulu-Natal. Pp. 187199. Available at: http://www.infs.ukzn.ac.za/kiad/13kaniki.doc. Accessed 20 August 2009.

Kwake, A. and Ocholla, D. N. 2007. The feasibility of ICT diffusion amongst African rural women: a case study of South Africa and Kenya. International 
review of information ethics 7 . Available at: http://www.i-r-i-e. et/inhalt/007/03wafula-kwake.pdf. Accessed 20 July 2009.

Lesaoana-Tshabalala, B. V. 2003. Agricultural information needs and resources available to agriculturalists and farmers in a developing country with special reference to Lesotho. MA thesis. Pretoria: University of Pretoria, Information Studies Department. Available at: http://etd. au.ac.za/theses/available/etd03242004-125946/restricted/ThabalaThesesFinal.pdf._Accessed 2 April 2007.

Matovelo, D. S., Msuya, J. and de Smet, E. 2006. Towards developing proactive information acquisition practices among smallholder farmers for empowerment and poverty reduction: a situation analysis. International Association of Agricultural Information Specialists (IAALD) quarterly bulletin 51 (3-4): 256264.

Mchombu, K. J. 2001. Research on measuring the impact of information on rural development. In Stilwell, C., Leach, A. and Burton, S. (eds). Knowledge, information and development: an African perspective. Pietermaritzburg: University of KwaZulu-Natal. Pp. 229-238. Available at: http://www.infs.ukzn.ac.za/kiad/16mchom.doc. Accessed 14 November 2007.

Mchombu, K. J. 2003. Information dissemination for development: an impact study. Information development 19 (2): 111-125.

Meitei, L. S. and Devi, T. P. 2009. Farmers information needs in rural Manipur: an assessment. Annals of Library and Information Studies 56: 35-40.

Ministry of Agriculture and Food Security in Tanzania (MAFS) of the United Republic of Tanzania. 2001. Agricultural sector development strategy. Paper read at the Tanzania Agricultural Sector Stakeholders Meeting, Dodoma. Available at: http://www.tzonline.org/pdf/agriculturalsectorstrategy.pdf. Accessed 16 June 2007.

Momodu, M. O. 2002. Information needs and information seeking behaviour of rural dwellers in Nigeria: a case study of Ekpoma in Esan West local government area of Edo State, Nigeria. Library review 51 (8): 406-410.

Mooko, N. P. 2005. The information behaviours of rural women in Botswana. Library and information science research 27 (1): 115-127. 
Njoku, I. F. 2004. The information needs and information seeking behaviour of fishermen in Lagos state, Nigeria. The international information and library review 36 (4): 297-307.

Ochieng, O. 2004. Kenyan initiatives to take science to its farmers. SciDev.Net Available at: http://allafrica.com/200502150673.html. Accessed 22 February 2007.

Patton, M. Q. 2002. Qualitative research and evaluation methods. $3^{\text {rd }}$ ed. Thousands Oaks: Sage Publications.

Pickard, A.J. 2007. Research methods in information. London: Facet Publishing.

Röling, N. G. 1989. The research/extension interface a knowledge system perspective. International Service for National Agricultural Research (ISNAR) staff notes. The Hague: ISNAR.

Sekaran, U. 2003. Research methods for business: a skill-building approach. 4th ed. New York: John Wiley.

Teddlie, C. and Tashakkori, A. 2009. Foundation of mixed methods research: integrating quantitative and qualitative approaches in the social and behavioural sciences. Thousand Oaks: Sage.

Tire, M. 2006. An evaluation of the information dissemination mechanisms for small scale subsistence farmers. MA. Philosophy. University of Stellenbosch, Cape Town. Available at:

http://ir.sun.ac.za/dspace/bitstream/10019/135/1/TireM.pdf. Accessed 13 June 2007.

United Republic of Tanzania (URT). 2009a. Budget Speech 2009/10 of the Ministry of Agriculture and Food Security. Available at: www.parliament.go.tz. Accessed 6 August 2009.

Wilson, T. D. 1981. On user studies and information needs. Journal of librarianship 237 (1): 3-15. Available at:

http://informationr.net/tdw/publ/papers/1981infoneeds.html. Accessed 22 August 2009. 
Wilson, T. D. 1996. Information behaviour, an interdisciplinary perspective. British Library Research and Innovation Report 10. Available at: http://informationr.net/tdw/publ/infbehav/cont.html. Accessed 20 September 2008.

Wilson, T.D. 2000. Human information behaviour. Informing sciences 3 (2): 49-55.

Zaverdinos-Kockott, A. 2004. An information needs assessment in Oribi Village, Pietermaritzburg. Innovation 29: 13-23. Available at: http://www.innovation.ukzn.ac.za/InnovationPdfs/No29pp13-23ZaverdinosKockott.pdf. Accessed 16 June 2009.

\section{Endnotes}

${ }^{1}$ Information and knowledge on processing, crop storage and packaging.

2 This paper was originally published in Journal of Documentation, 37(1), 1981, 3-15 as cited in Stilwell (2010) in this issue. 